\title{
Use of biplot approach for genetic analysis of yield and related traits in cotton (Gossypiumbarbadense)
}

\author{
H. M. E. Hamoud \\ Cotton Research Institute, Agriculture Research Center, Giza, Egypt. \\ Received 17 November, 2013; Accepted 17 December, 2013
}

\begin{abstract}
Combining ability is an important genetic attributes to cotton breeders in anticipated improvement via hybridization and selection. Seven parents were involved in a half diallel mating design which was analyzed by genotype $\times$ environment interaction (GGE) biplot graphical method. General combining ability (GCA) and specific combining ability (SCA) effects were significant for all traits. None of the parents were found to be a good combiner for all traits. The combinations of Giza $75 \times$ Sea, $10229 \times$ Giza 86 and Giza 86 had the best SCA for seed cotton yield/plant, lint percentage and boll weight, respectively. The graphical demonstration proposed by the biplot analysis provided an effective overview of GCA and SCA effects and mean performances in crosses. In addition, the biplot also provided an opportunity for assessing the interrelationship among the genotypes.
\end{abstract}

Key words: Cotton, diallel, biplot, correlation, general combining ability, specific combining ability.

\section{INTRODUCTION}

In terms of production and value, cotton is still a very important crop in Egypt. The whole plant has commercial use directly or indirectly and also has capability to meet the demand for natural fiber and oil. However, fluctuation in price and high cost of production affect negatively on cotton in dedicated area from year to year. The crop has been gradually forced out of the Delta region and cultivated under marginal conditions. Therefore, varieties suitable for new conditions need to be developed through appropriate hybridization and selection techniques. Combining ability estimates provide information useful for the selection of parents and also provides information regarding the nature and magnitude of gene action involved. The knowledge of genetic structure and made of inheritance of different characters helps breeders to select appropriate breeding methodology (Kiani et al.,
2007). Diallel crossing was usually done by using Griffing's methods (1956). These methods are less interpretative, difficult to understand without the aid of some graphical display (Dehghani et al., 2012), Yan and Hunt (2002) have developed a quick evaluation method called GGE biplot model for analyzing the diallel data, this technique enhances the capability of interpreting the phenotypic variation to obtain combining ability and interrelationships of parents based on graphical presentation using PC1 and PC2 which are derived through PC analysis of environment-centered yield data. GGE biplot is recent method and has been widely used to determine combining ability and heterotic responses (Shang et al., 2006; Darvishzadeh et al., 2009). The GGE biplot methodology was developed for multi-environments trial (MET) data, in which, genotypes are entries and 
Table 1. Origin and abbreviation for each genotype.

\begin{tabular}{lllll}
\hline Entry code & Tester code & Origin & Categories & Current position \\
\hline G86 & g86 & Giza 86 & Long staple & Commercial variety \\
G93 & g93 & Giza 93 & Extra long staple & Commercial variety \\
G92 & g92 & Giza 92 & Extra long staple & Commercial variety \\
G75xS & g75xS & Giza $75 \times$ Sea & Long staple & New promising hybrid \\
$10 x G 86$ & $10 \times 986$ & $10229 \times$ Giza 86 & Long staple & New promising hybrid \\
G85 & g85 & Giza 85 & Long staple & Commercial variety \\
G88 & g88 & Giza 88 & Long staple & Commercial variety \\
\hline
\end{tabular}

environments are testers. Yan's GGE biplot is also preferred to the conventional diallel approach because it gives jointly GCA and SCA effects of the population and the preferences of the crosses as well as grouping pattern of similar genotypes (Bertoia et al., 2006). The present study was undertaken to analyze diallel data using GGE biplot model to gather information about genetic interrelationships among parents, general and specific combining ability and to identificate heterotic combination for three important traits, that is, seed cotton yield (SCY/P), lint percentage (L\%) and boll weight (BW).

\section{MATERIALS AND METHODS}

Five varieties and two promising crosses from different categories in Egyptian cotton (Table 1) were used in this study. These genotypes were crossed following in a half diallel fashion to produce $28 F_{1}$ crosses during season 2011 . All the $F_{1}$ crosses were evaluated along with parents in the following season with the planting date of April 24, 2012 at Sakha Agriculture Research Station under two system of irrigation. The first system was normal irrigation system that irrigated at about 15 day's intervals; the other one was under drought regime which irrigated at 30 day's intervals both irrigation systems, a randomize complete block design was used with three replication for each genotypes and each replication consisting of one row $(4 \mathrm{~m}$ long, $70 \mathrm{~cm}$ wide, $40 \mathrm{~cm}$ between hells and one plant per hell after thinning). Standard cultural practices were applied uniformly at all experimental units. Six plants from each plot were separately harvested to estimate the three traits, seed cotton yield/plant $(\mathrm{SCY} / \mathrm{P})$, lint percentage $(\mathrm{L} \%)$ and boll weight (BW).

An analysis of variances (ANOVA) was done using average environments values. Griffing's (1956) method 2 model 1 (fixed effect of parents) was applied to estimate GCA and SCA. The significance of genotypes, GCA and SCA mean squares were estimated using $\mathrm{F}$ test.

In GGE biplot, mean and stability of genotypes referred to GCA and SCA parents, respectively. The mean values for hybrids and parental populations across environments are used to form a symmetrical diallel data matrix from which the first two principle component (PC1 and PC2) were extracted. Each population corresponded to one row and one column of data, after obtaining the first two principle component of the adjusted data. The model for data analysis is:

$Y i j-\beta j=\lambda 1 \varepsilon i 1 \eta j 1+\lambda 2 \varepsilon_{i 2} \eta_{j 2}+\varepsilon i j$

Where $Y_{i j}$ is genotypic values of the combination between entry $i$ and tester $j$ for a given trait; $\beta j$ average value of all combinations with tester $\mathrm{j}, \lambda 1$ and $\lambda 2$ are singular values for $\mathrm{PC} 1$ and PC2. $\varepsilon 11$ and $\varepsilon \mathrm{i} 2$ are PC1 and PC2 eigenvectors for entry i, respectively; $\eta j 1$ and $\eta j 2$ are $P C 1$ and $P C 2$ eigenvectors for tester $\mathrm{j}$, respectively; $\varepsilon \mathrm{ij}$ is the residual of model for entry $\mathrm{i}$ and tester $\mathrm{j}$. In diallel crosses, a parent is both an entry and a tester. This statistical method has been described by Yan and Hunt (2002) and Yan and Kang (2003). This analysis is done using GGE biplot software (Yan, 2001).

The analysis of interrelationship between parents entries/testers can be approximated by cosine of the angle between parents:

$\cos ($ aij $)=$ rij

Where, aij is the angle between parent $\mathrm{i}$ and parent $\mathrm{j}$ and rij is the correlation coefficient between both parents. Two parent are positively correlated if the angle between their vectors is $<90^{\circ}$, negatively correlated if the angle is $>90^{\circ}$, and independent if the angle between them is $90^{\circ}$. $0^{\circ}$ means correlation $(r)$ is 1 and 180 means correlation is -1 . Entry with longer vector are more discriminating of the entries, those with short vectors are less discriminating and those located at the biplot origin are not discriminating.

The GCA and SCA effects of entries were examined by drawing an average tester coordinate (ATC) abscissa view for entries. The GCA effect of the entries was approximated by the projection of their markers to the ATC abscissa (the single arrowed lines) with the direction indicating the positive end. While the SCA of the entries was approximated by the projection of their markers to the ATC ordinate (double arrowed line) (Yan and Hunt, 2002). The polygon view of the biplot is drawn by connecting the entries. The perpendicular line to each side drawn from the origin of the plot divides the biplot into several sectors, and each tester falls into one sector. Tester falling in a sector shares the best mating partner with another entry present at the vertex of the polygon in that sector. Entries located near the biplot origin are less responsive to change of the testers.

\section{RESULTS AND DISCUSSION}

The analysis of variance (Table 2) showed widespread significant differences among genotypes suggesting a great level of genetic variability to among the parents for all traits. GCA and SCA based on conventional method (Griffing's model) showed high significance suggesting the role of both additive and non-additive gene action. For seed cotton yield/plant and boll weight, the ratio of $\left(\delta^{2}\right.$ of $\mathrm{GCA}) /\left(\delta^{2}\right.$ of SCA) was less than one indicating nonadditive gene action in the inheritance of these traits. Meanwhile, for the lint percentage the ratio of $\left(\delta^{2}\right.$ of 
Table 2. Analysis of variance and variances and estimates of combining ability for seed cotton yield, lint percentage and boll weight.

\begin{tabular}{lcccc}
\hline Source of variation & df & SCY/P & L\% & BW \\
\hline Replication & 2 & 119.5 & 0.147 & 0.071 \\
Genotypes & 27 & $1348.6^{* *}$ & $4.235^{* *}$ & $0.150^{* *}$ \\
Error & 54 & 315.62 & 0.750 & 0.018 \\
Combining ability variances & & & & \\
GCA & 6 & $772.2^{* *}$ & $3.463^{* *}$ & $0.086^{* *}$ \\
SCA & 21 & $357.3^{* *}$ & $0.825^{* *}$ & $0.040^{* *}$ \\
Error & 4 & 105.21 & 0.250 & 0.006 \\
Combining ability estimates & & & \\
$\delta^{2}$ of GCA & & 66.699 & 0.3213 & 0.008 \\
$\delta^{2}$ of GCA & & 126.045 & 0.2875 & 0.017 \\
( $\delta^{2}$ of GCA $\delta^{2}$ of SCA) & & 0.727 & 1.057 & 0.685 \\
S.Eg & & 3.42 & 0.154 & 0.023 \\
S E sij & 9.21 & 0.448 & 0.061 \\
\hline
\end{tabular}

**Significant at the 0.01 probability level.

$\mathrm{GCA}) /\left(\delta^{2}\right.$ of SCA) was more than one indicating additive gene action was predominant for the trait.

\section{Seed cotton yield/plant (SCY/P)}

In GGE biplot, the graphical representation of concentric ring with vectors showed that parental Giza75x Sea had the longest vector (the largest variation), while parents Giza 85 and 10229 x Giza 86 had the shortest vectors (the lowest variation) as seen in Figure A1. The vectors of the parent Giza 85 with the all parents except Giza75x Sea and Giza 92 had acute angle (less than $90^{\circ}$ ), which suggests positive correlations among them. The parent Giza75 x Sea had obtuse angle with 10229 x Giza 86, Giza 85, Giza 86 and Giza 88 which suggests lowest correlations among them and should produce heterosis crosses. Meanwhile, Giza $75 \times$ Sea had acute angle with Giza 92. The angle between Giza 75 x Sea and Giza 93 was $90^{\circ}$, which means independent relation between them.

The biplot for seed cotton yield explained $73 \%$ (50 and $23 \%$, by PC1 and PC2) of the total variation in Figure A1, Hamoud et al. (2012) reported $86.6 \%$ of variation for sum of PC1 and PC2 for the same trait. The remaining proportion of the total variation was not accounted by biplot analysis due to much complexity in genetics involved in this trait among the seven parents.

As shown in Figure A2 entry Giza75 x Sea and Giza 92 had the largest projection onto ATC (Average tester coordination) abscissa exhibiting the highest and positive GCA effect for seed cotton yield / plant. Whereas, the entries 10229 x Giza 86, Giza85, Giza G88, Giza 93 and Giza 86 were located on the left side of the ATC ordinate (in the opposite direction of ATC abscissa) indicating the lowest and negative GCA effects. Entry Giza 92 followed by Giza75 x Sea and Giza 93 had highest SCA based on the largest projections onto the ATC ordinate. Whereas entry Giza 86, Giza 88 and Giza 85 showed the smallest SCA effects (small projection on ATC ordinate). Based on heterosis, two different groups were suggested in in Figure A2. First group contained Giza $75 \times$ Sea and Giza 93 and the other contained Giza 92. Meanwhile, the others entries located in intermediate positions. Therefore, two crosses, that is, (Giza 75 × Sea) x Giza 92 and Giza 93 x Giza 92 are expected to be heterotic, better than their parents.

Figure A3 provided the best way to demonstrate the interaction patterns between entries and testers as mentioned by Yan et al. (2000) and Yan and Hunt (2002). Four entries are on the vertex on which they have the largest distances from the origin. The polygon view provides a way to group testers based on their best mating partners. Testers falling in the same sector share the same best mating partner and those falling in different sectors have different best mating partners. Subsequently the entry Giza $75 \times$ Sea is the best mating partner for Giza 92, 10229 x Giza 86, Giza 85 and Giza 88. Giza $75 \times$ Sea had the highest GCA, because four of the other seven testers were located in this sector. Moreover, the parent Giza 75 x Sea, as a tester was not found in this sector, so heterosis was suggested in hybrids Giza 75 x Sea with the testers (Giza 92, Giza 85, Giza 88 and $10229 \times$ Giza 86). In the same manner, Giza 92 was in the second arrange for GCA, because 3 testers (Giza 93, Giza 86 and Giza 75 x Sea) were located in this sector. The parent Giza 92 as a tester was not found in sector Giza 92 as entry, so heterosis was suggested in 

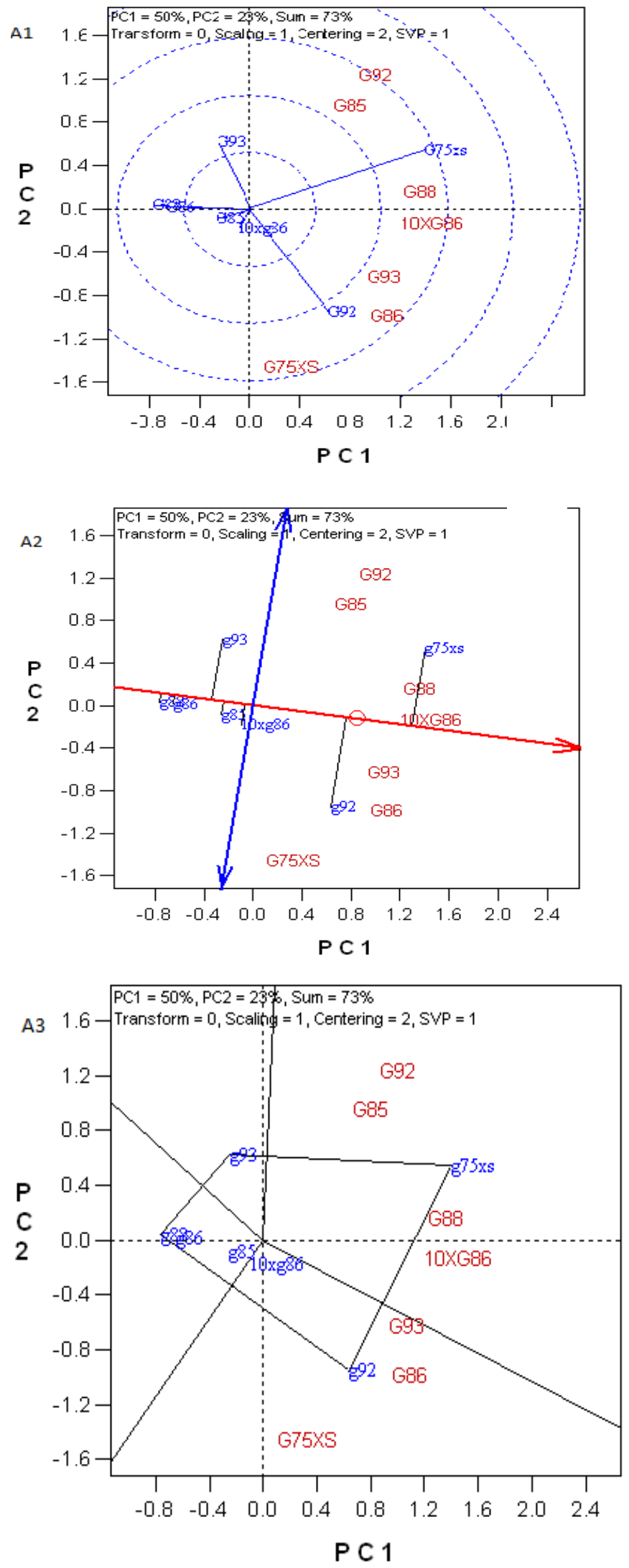

Figure 1. Biplot based on dialled data of seven cotton genotypes of seed cotton yield (scy/p). (A1) Relationship among entries; (A2) Average tester co-ordination; (A3). Polygon view. the hybrids of Giza 92 with the testers (Giza 93, Giza 86 and Giza $75 \times$ Sea). Rastogi et al. (2011) reported that all the heterotic crosses obtained through biplot analysis showed similar heterotic effects for same crosses analyzed manually by following standard formula. Meanwhile, no tester fell in sectors of Giza 93 and Giza 88 , indicating that entries were not the best partner with any of the other testers. In addition, in sector of Giza $75 x$ Sea, Giza 75 x Sea was predicted to be the best mating partner for Giza 92 and in sector of Giza 92, Giza 92 was also predicted to be the best mating partner for Giza $75 x$ Sea. Giza 75 x Sea and Giza 92 were therefore identified to be the best partner for each other, and the cross (Giza $75 \times$ Sea) $x$ Giza 92 must be the best of all possible combination (Yan and Kang, 2003).

\section{Lint percentage (L\%)}

Graphical representation of centric ring system in Figure B1 revealed that the parent $10229 \times$ Giza 86 had the largest vector and so had the largest variation. Meanwhile the parents Giza 88, Giza 93 and Giza 75 x Sea had the lowest variation which were located at the same circle around origin. The parents 10229 x Giza 86 with Giza 88, and Giza 92 with each of Giza 86 and Giza $75 \times$ Sea had the acute angles, which suggests positive correlations among them. Meanwhile, $10229 \times$ Giza 86 with Giza 93, Giza 86, Giza 92 and Giza 75 x Sea had obtuse angles, which suggests negative correlations. Independent relation was found between $10229 \times$ Giza 86 and Giza 85 because the angle between them equal to $90^{\circ}$.

Figure B2 showed that GCA and SCA biplot explained $83 \%$ of variation $(P C 1=65.3 \%, P C 2=17.7 \%)$. Hamoud et al. (2012) reported that PC1 and PC2 explained 95.9\% of total variation. GCA for entries increased in the direction of arrow on ATC (average tester coordination) abscissa. The parents on the right of the ATC ordinate had positive GCA, while the other parents had negative GCA. The ranking of the entries for GCA was: $10229 x$ Giza 86> Giza 88 > Giza 85 > Giza 93 > Giza 75 x Sea > Giza $86>$ Giza 92.

For SCA, unlike the conventional methods of diallel analysis, which gave an insight only into SCA of crosses (Bocanski et al., 2011) biplot analysis enables the SCA of the parent to estimate. Based on projections on the ATC ordinate, that the highest SCA related to Giza 85 and the lowest was found for Giza 92 and Giza 88.

The biplot in Figure B3 provided the best way to demonstrate the interaction patterns between entries and testers as mentioned by Yan et al. (2000) and (Yan and Hunt (2002). A polygon view is shown in the biplot such that six entries are on the vertices while one is inside the polygon. Since the vertex entries have the largest distances from the origin, they are most responsive to the change of testers relative to other entries within respective groups. The biplot was divided into six sectors. The testers 

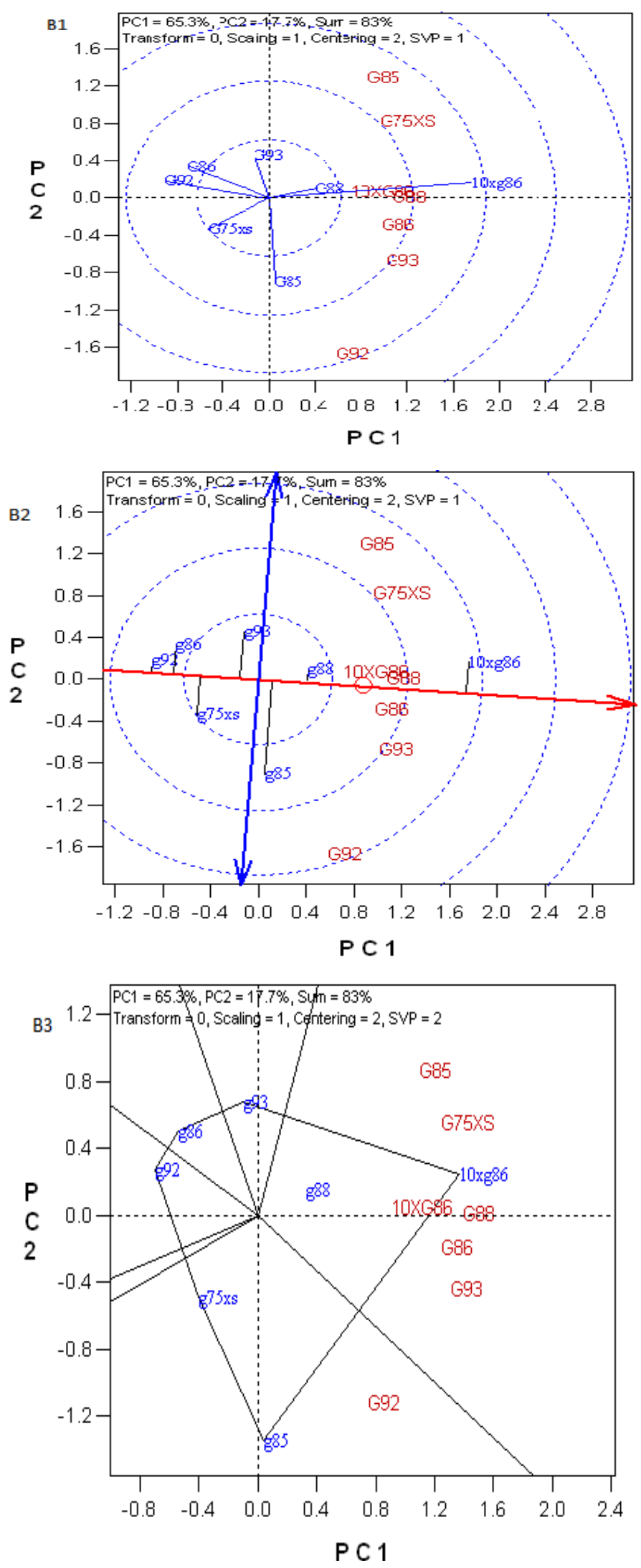

Figure 2. Biplot based on dialled data of seven cotton genotypes for lint percentage (L\%). (B1) Relationship among entries; (B2) Average tester co-ordination; (B3). Polygon view.
Giza 85, Giza 75 x Sea, Giza 86, Giza 93 and Giza 88 fell in the sectors that have the vertex $10229 \times$ Giza 86. The biplot clearly shows why $10229 \times$ Giza 86 had the highest GCA, since it was the vertex entry in a sector in which four of the other seven testers, are Giza 85, Giza $75 x$ Sea, Giza 86, and Giza 93. Since tester 10229 x Giza 86 fell in sector $10229 \times$ Giza 86, the combination (10229 x Giza 86) x (10229 x Giza 86) would be the best among all crosses involving $10229 \times$ Giza 86 and therefore heterosis between $10229 \times$ Giza 86 and any of the other parents is not possible. Meanwhile, the only tester Giza 93 is located in the sector that has the vertex Giza 85 which represents the best mating partner. For the other sectors including Giza 93, Giza 86, Giza 92 and Giza 75 $x$ Sea, there is no testers fell in, indicating that these parents were not the best partner with any of the other parents

\section{Boll weight (BW)}

Biplot explained $75 \%$ of variation in BW (50 and $25 \%$, by PC1 and PC2, respectively) (Figure C1). The interrelationships among genotypes are visualized in Figure C1. The entry Giza 93 is very close to Giza 85 and Giza 88 is very close to the entries 10229 x Giza 86 and Giza 86 , which have angles $<90^{\circ}$, and predict positive relationships among them. However, the negative relationship was observed between Giza 86 and each of Giza 85 and Giza 93, and negative relationship between Giza 75 x Sea and each of 10229 x Giza 86 and Giza 88, which have angle $>90^{\circ}$ indicating that these genotypes were apparently different. The entry Giza 92 is located very close to origin, which implies the lowest discriminate entry.

GCA and SCA can be detected from in Figure C2. Based on the projections onto abscissa, the entries ranking for GCA were: Giza 86 > Giza 88 > 10229 x Giza $86>$ Giza 75 x Sea $\approx$ Giza 92> Giza $93 \approx$ Giza 85. AbdelBary et al. (2008) reported that Giza 86 was the best combiner for boll weight. To display SCA effects of the entries, the vector length helps in ranking the entries as shown in Figure C2. Since the entry Giza $75 \times$ Sea has the longest projection on the ATC ordinate (located on the same perpendicular line which had the grand mean for GCA for all traits) exhibiting that it has the highest SCA effects for boll weight. Similarly, Giza 86 and 10229 $x$ Giza 86 followed by Giza 88 showed positive SCA effects. Whereas, the entries Giza 92 and Giza 85 showed smallest the SCA effects (small projection on to ATC ordinate).

Polygon view in biplot as shown in Figure C3. Five entries are on the vertices while two are inside the polygon. Since the vertex entries have the largest distance from the origin; they are the most responsive to the change of testers relative to other entries within respective groups. The sector that has the vertex Giza 86 contains several testers, that is, $10229 \times$ Giza 86, Giza 

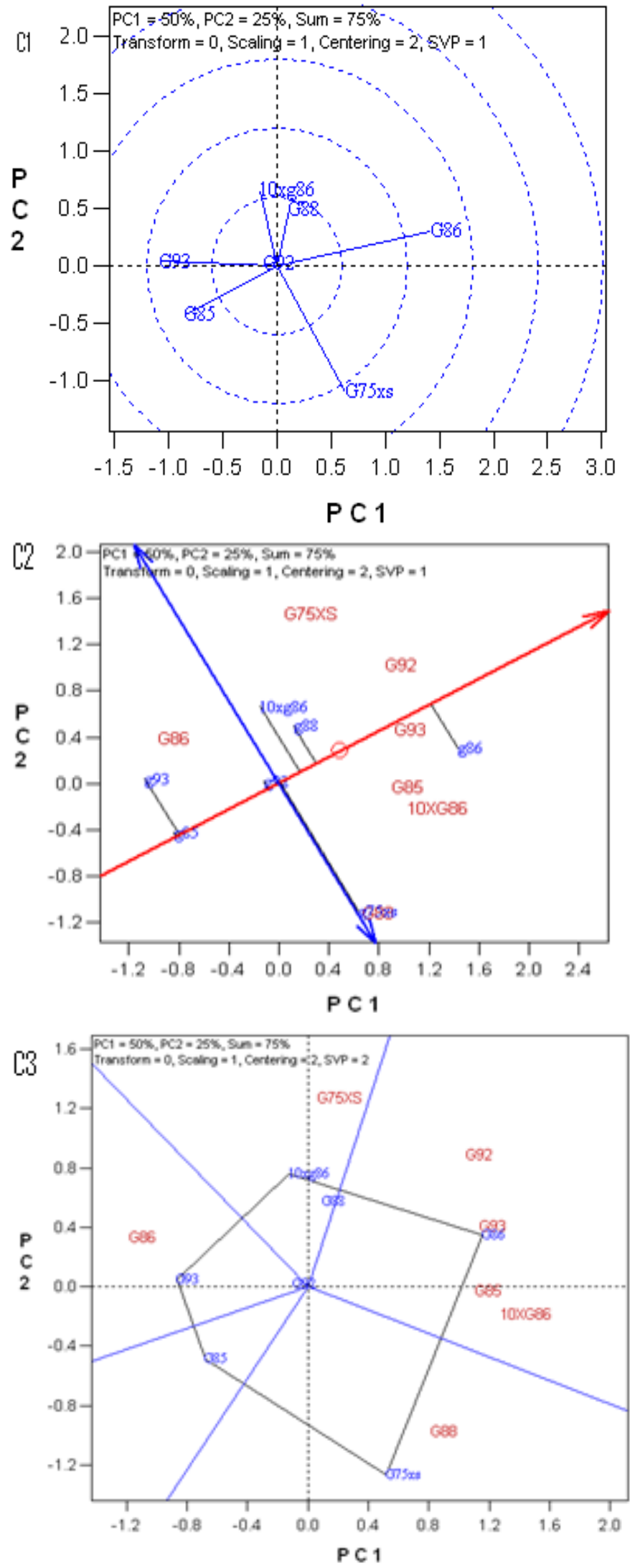

Figure 3. Biplot based on diallled data of seven cotton genotypes for boll weight (b. w). (C1) Relationship among entries; (C2) Average tester co-ordination; (C3). Polygon view.
85, Giza 93 and Giza 92. The biplot clearly shows why entry Giza 86 had the highest GCA effect because it was the vertex entry in a sector in which four testers from seven fell. Also, in each of the next three sectors $10229 x$ Giza 86, Giza 93 and Giza 75 x Sea only a single tester, that is, Giza 75 x Sea, Giza 86 and Giza 88 can be seen. These represent the three best mating partners including (10229 x Giza 86) x (Giza 75 x Sea), Giza 93 x Giza 86 and (Giza 75 x sea) x Giza88.

\section{Conclusion}

The significance of GCA and SCA effects discovered in this study suggested the importance of both additive and non-additive gene action for all traits under investigation in cotton. The study evidently proved the authenticity of Yan's model is useful for analysis of diallel data. The first advantage of the biplot is its graphical presentation of the diallel data, which greatly enhances our ability to understand the patterns of data. The second is that it is more interpretative. Third is its display of a complete picture of the interrelationship among parents. Several researchers have used this method to analyze and interpret diallel data (Khalil et al., 2010; Borghi et al., 2012).

\section{Conflict of Interests}

The author(s) have not declared any conflict of interests.

\section{REFERENCES}

Abdel-Bary AMR, Soliman YAM, Hamoud HME, Abou-Elyazied, (2008). Triallel analysis for yield components and fiber traits in Gossypium barbadence L. J. Agric. Sci. Mansoura Univ. 33(2):1189-1201.

Bertoia L, Lopez C, Burak R (2006). Biplot analysis of forage combining abiliy in maize landraces. Crop Sci. 46(3):1346-1353. http://dx.doi.org/10.2135/cropsci2005.09-0336

Bocanski J, Nastasic A, Stanisavljevic D, Zorana S, Mitrovic B, Treskic S, Vukosavljev M (2011). Biplot analysis of diallel crosses of NS maize. J. Genetika 43(2):277-284. DOI: 10.2298/GENSR1102277B

Borghi ML, Iba-ez MA, Bonamico NC, Kandus MV, Almorza D, Gomar, Guillin EA, Salerno JC, Di Renzo MA (2012). Combining ability of flint corn inbred lines: Mal de Río Cuarto disease tolerance and grain yield. $\phi$ YTON ISSN 0031 81:123-131.

Darvishzadeh R, Bernousi I, Poormohammad-Kiani S, DechampGuillaume G, Sarrafi A (2009). Use of GGEbiplot methodology and griffings diallel method for genetic analysis of partial resistance to phoma black stem disease in sunflower. Acta Agric. Scand. Plant Soil Sci. 59:485-490. DOI:10.1080/09064710802282747

Dehghani H, Fayzian SE, Jalali M, Rezai A, Dane F (2012). Use of GE biplot methodology for genetic analysis of yield-related traits in melon (Cucumis melo L.). Can. J. Plant Sci. 92:77-85. http://dx.doi.org/10.4141/cjps2010-046

Griffing B (1956). Concept of general and specific combining ability in relation to diallel crossing systems. Austr. J. Biol. Sci. 9:463-493. doi:10.1071/BI9560463

Hamoud HME, Abd AMR, El-Bary WMB, Yehia MM, Soliman YA (2012). Application of AMMI model and GGE biplot analysis of Multienvironments Trials Data in Egyptian cotton. The 11th Alexandria 
International Cotton Conference 17 -18 April.

Khalil IM, Rahman H, Saeed N, Khan NU (2010). Combining ability in maize single cross hybrids for grain yield; a graphical analysis. Sarhad. J. Agric. 26:3.

Kiani G, Nematzadeh GA, Kazemitabarand SK Alishah O (2007). Combining ability in cotton cultivars for agronomic traits. Int. J. Agric. Biol. 9:521-522.

Shang YI, Shao-Qin LI, Dian-Rong LI, Jian-Hual T (2006). GGE biplot analysis of diallel cross of Brassica napus L. Acta Agron. Sin. 32:243248.

Rastogi A, Mishra KB, Srivastava M, Siddiqui A, Shukla S (2011). Biplot approach for identification of heterosis crosses in linseed (Linum usitatissimum L). J. Agric. Sci. Tech. P. 15. http://dx.doi.org/10.1155/2011/353102

Yan W, Hunt LA (2002). Biplot analysis of diallel data. Crop Sci. 42:2130.http://dx.doi.org/10.2135/cropsci2002.0021PMid:11756249

Yan W (2001). GGE biplot a Windows application for graphical analysis of multi-environments trial data and other types of two way data. Agron. $\mathrm{J}$.

93:1111-1118.
Yan W, Kang MS (2003). GGE biplot analysis: A graphical tool for breeders geneticists, and agronomists. CRC Press, New York, NY.

Yan W, Hunt LA, Sheng Q, Szlavnics Z (2000). Cultivar evaluation and mega-environment investigation based on the GGE biplot. Crop Sci. 40:597-605. http://dx.doi.org/10.2135/cropsci2000.403597x 